See Article page e361.

\section{Commentary: Small packages, big questions: Mitochondrial transplantation in a preclinical model of pulmonary arterial hypertension}

\author{
Eric J. Charles, $\mathrm{MD}, \mathrm{PhD},{ }^{\mathrm{a}}$ and
}

Bradley M. Wertheim, MD ${ }^{\mathrm{b}}$

Pulmonary arterial hypertension (PAH) is a progressive and debilitating condition, with a 5-year survival of $40 \%$ to $70 \%$ in the contemporary era, depending on the clinical context. ${ }^{1}$ Pulmonary vasodilators targeting the endothelin, nitric oxide, and prostacyclin pathways have improved clinical outcomes, but therapies that directly address vascular remodeling are critically needed. ${ }^{2}$ Predicated on the notion that mitochondrial dysfunction constitutes a central role in the pathophysiology of $\mathrm{PAH}$, Hsu and colleagues ${ }^{3}$ examined the effect of intravenous systemic delivery of allogeneic soleus muscle mitochondria in a rat model of monocrotaline-induced pulmonary vascular injury paired with left-to-right shunt, which approximates the pathophysiology of PAH arising from uncorrected congenital heart disease. $^{4}$

Mitochondrial transplantation (MT) has been reported to attenuate cardiac ischemia-reperfusion injury and hypoxic pulmonary hypertension in preclinical studies. ${ }^{5-7}$ Similarly, intercellular mitochondrial transfer can rescue aerobic respiration in cells with nonfunctional mitochondria. ${ }^{8} \mathrm{How}-$ ever, the mechanism remains undefined and challenging to square with other findings that mitochondria ex vivo may

\footnotetext{
From the ${ }^{a}$ Division of Cardiac Surgery, Department of Surgery, University of Virginia, Charlottesville, Va; and ${ }^{\mathrm{b}}$ Division of Pulmonary and Critical Care Medicine, Department of Medicine, Brigham and Women's Hospital, Harvard Medical School, Boston, Mass.

Disclosures: The authors reported no conflicts of interest.

The Journal policy requires editors and reviewers to disclose conflicts of interest and to decline handling or reviewing manuscripts for which they may have a conflict of interest. The editors and reviewers of this article have no conflicts of interest.

Received for publication Sept 14, 2020; revisions received Sept 14, 2020; accepted for publication Sept 15, 2020; available ahead of print Sept 19, 2020.

Address for reprints: Eric J. Charles, MD, PhD, Department of Surgery, University of Virginia, PO Box 800679, Charlottesville, VA 22908 (E-mail: ec4wx@virginia. edu).

J Thorac Cardiovasc Surg 2022;163:e379-80

0022-5223/\$36.00

Copyright (C) 2020 by The American Association for Thoracic Surgery

https://doi.org/10.1016/j.jtcvs.2020.09.061
}

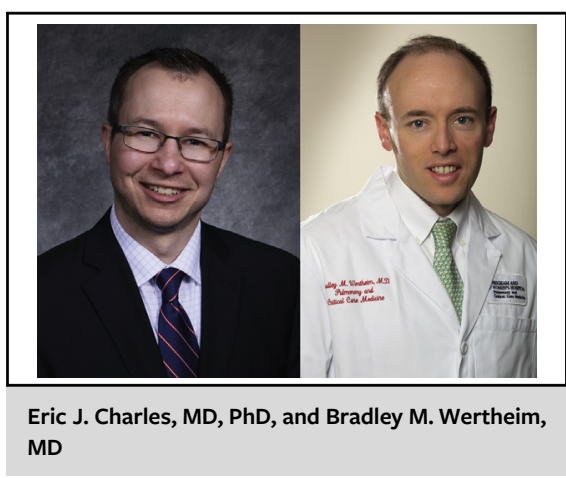

CENTRAL MESSAGE

Intravenous delivery of mito-

chondria is associated with

improved surrogate end points

in experimental pulmonary arte-

rial hypertension. Further inves-

tigation is required before clinical

translation.

become irreversibly depolarized when exposed to calcium concentrations found in extracellular fluid and blood.

In the current report by Hsu and colleagues, ${ }^{3}$ MT conferred no survival advantage. Nonetheless, histologic improvement in arteriolar medial thickness, serum brain natriuretic peptide concentration, right ventricular (RV) hypertrophy, vascular reactivity ex vivo, and a modest decrease in tricuspid regurgitation jet velocity was seen. Cardiac catheterization with measurement of pulmonary vascular resistance, the gold-standard metric for hemodynamic assessment in PAH, was not performed, which is a major study limitation. The authors conclude that transplanted mitochondria incorporate into the pulmonary vasculature of rats with congenital heart disease-PAH to increase whole lung adenosine triphosphate content, abrogate vascular smooth muscle cell dysfunction, and partially attenuate vascular remodeling, although limited molecular and metabolic data were provided to support this model.

The findings raise a number of important questions for future investigation. Foremost, it remains to be answered whether the observed effects of MT are mediated by mitochondrial metabolic activity, a mediator that cofractionates with the mitochondrial preparation, or an induced host response. ${ }^{6,9,10}$ Additional data are needed to better define the biological composition of the donor mitochondrial fraction, the biofunctionality of the donor 
organelles ex vivo and in vivo, pharmacokinetics, localization of donor mitochondria in the vascular and/or subcellular compartments, and host response to MT; in turn, this may allow for refinement and optimization of therapeutic effect. As no current preclinical model recapitulates the complex phenotype of human PAH, the findings of this study would be strengthened by examination of MT in additional models, along with invasive RV pressure-volume loop analysis to independently characterize changes in RV contractility and afterload. Finally, the lack of survival benefit in MT-treated animals, despite histologic improvement in pulmonary arteriolar remodeling, could suggest off-target toxicities, which must be more systematically assessed.

Collectively, the report by Hsu and colleagues ${ }^{3}$ provides additional data to continue preclinical investigation of MT for PAH. However, much work remains to establish the efficacy, mechanism, and safety of this approach before clinical translation.

\section{References}

1. Benza RL, Miller DP, Barst RJ, Badesch DB, Frost AE, McGoon MD An evaluation of long-term survival from time of diagnosis in pulmonary arterial hypertension from the REVEAL registry. Chest. 2020;142:448-56.

2. Galiè N, Barberà JA, Frost AE, Ghofrani HA, Hoeper MM, McLaughlin VV, et al. Initial use of ambrisentan plus tadalafil in pulmonary arterial hypertension. N Engl J Med. 2015;373:834-44.

3. Hsu C-H, Roan J-N, Fang S-Y, Chiu M-H, Cheng T-T, Huang C-C, et al. Transplantation of viable mitochondria improves right ventricular performance and pulmonary artery remodeling in rats with pulmonary arterial hypertension. J Thorac Cardiovasc Surg. 2022;163:e361-73.

4. Bonnet S, Michelakis ED, Porter CJ, Andrade-Navarro MA, Thébaud B, Bonnet $\mathrm{S}$, et al. An abnormal mitochondrial-hypoxia inducible factor- $1 \alpha-\mathrm{Kv}$ channel pathway disrupts oxygen sensing and triggers pulmonary arterial hypertension in fawn hooded rats: similarities to human pulmonary arterial hypertension. Circulation. 2006;1132630-41.

5. McCully JD, Cowan DB, Pacak CA, Toumpoulis IK, Dayalan H, Levistsky S. Injection of isolated mitochondria during early reperfusion for cardioprotection. Am J Physiol Heart Circ Physiol. 2009;296:H94-105.

6. Zhu L, Zhang J, Zhou J, Lu Y, Huang S, Xiao R, et al. Mitochondrial transplantation attenuates hypoxic pulmonary hypertension. Oncotarget. 2016;7:48925-40.

7. Emani SM, Piekarski BL, Harrild D, Del Nido PJ, McCully JD. Autologous mitochondrial transplantation for dysfunction after ischemia-reperfusion injury. $J$ Thorac Cardiovasc Surg. 2017;154:286-9.

8. Spees JL, Olson SD, Whitney MJ, Prockop DJ. Mitochondrial transfer between cells can rescue aerobic respiration. Proc Natl Acad Sci U S A. 2006;103: 1283-8.

9. Bertero E, O'Rourke B, Maack C. Mitochondria do not survive calcium overload during transplantation. Circ Res. 2020;126:784-6.

10. Lee C, Mitsialis SA, Aslam M, Vitali SH, Vergadi E, Konstantinou G, et al. Exosomes mediate the cytoprotective action of mesenchymal stromal cells on hypoxia-induced pulmonary hypertension. Circulation. 2012;126:2601-11. 